CLINICAL STUDY

\title{
Evidence for association between paraoxonase 1 gene polymorphisms and polycystic ovarian syndrome in south-west Chinese women
}

\author{
Ying Wang ${ }^{1}$, Hongwei Liu ${ }^{1}$, Ping Fan $^{2}$, Huai Bai ${ }^{2}$, Jinxia Zhang ${ }^{2}$ and Feng Zhang ${ }^{1}$ \\ ${ }^{1}$ Department of Obstetrics and Gynecology and ${ }^{2}$ Laboratory of Genetic Disease and Perinatal Medicine and Key Laboratory of Obstetric and Gynecologic and \\ Pediatric Diseases and Birth Defects of Ministry of Education, West China Second University Hospital, Sichuan University, Chengdu 610041, Sichuan, \\ People's Republic of China \\ (Correspondence should be addressed to P Fan; Email: fanping15@yahoo.com.cn)
}

\begin{abstract}
Objective: The aim of this study was to investigate the relationship between $192 Q / R$ and $55 \mathrm{~L} / \mathrm{M}$ polymorphisms of paraoxonase 1 (PON1) gene and polycystic ovarian syndrome (PCOS) in Chinese women.

Design: A case-control study.

Methods: A total of 1113 subjects (610 patients with PCOS and 503 control women) from a population of Chinese Han nationality in Chengdu area were included in this study. PON1 genotypes were studied using PCR and restriction fragment length polymorphism analysis. Clinical and metabolic parameters were analyzed.

Results: The frequencies of PON1 192RR genotype and $R$ allele were significantly higher in patients with PCOS than in control women (44.6 vs $36.4 \%, 0.667$ vs 0.610 respectively). The $192 R R$ genotype remained a significant predictor for $\mathrm{PCOS}$ (odds ratio $\mathrm{RR} / \mathrm{OR}+\mathrm{QQ}: 1.656,95 \%$ confidence interval: 1.156-2.371) in prognostic models including age, body mass index, insulin resistance index, triglyceride, HDL, and LDL as covariates. Compared with patients with $Q Q$ genotype, patients with $R R$ or $Q R$ genotype had significantly higher waist circumference and fasting insulin and triglyceride levels, patients with $R R$ genotype had significantly higher waist-to-hip ratio, and patients with $Q R$ genotype had significantly higher homeostasis model assessment of insulin resistance. Such relationships were not detected in the control women. No significant differences were found in the frequencies of PON1 $55 \mathrm{~L} / \mathrm{M}$ genotype and allele between PCOS and control groups.

Conclusions: The $192 \mathrm{Q} / \mathrm{R}$, but not $55 \mathrm{~L} / \mathrm{M}$, polymorphism in PON1 gene is associated with the risk of PCOS in south-west Chinese women.
\end{abstract}

European Journal of Endocrinology 166 877-885

\section{Introduction}

Polycystic ovary syndrome (PCOS) is a heterogeneous female endocrine metabolic disorder affecting $5-10 \%$ of women of reproductive age and may account for anovulatory infertility and threaten long-term health $(1,2,3)$. PCOS represents a broad spectrum of metabolic alterations such as glucose intolerance, insulin resistance, dyslipidemia, obesity (especially the visceral phenotype), and increased oxidative stress $(2,4,5,6)$. Consequently, there is an increase in the risk factors for cardiovascular disease $(1,7)$, including hyperandrogenism (HA), impaired fibrinolysis, increased systemic low-grade inflammation, an elevated prevalence of subclinical and clinical atherosclerosis $(1,6)$, an increased prevalence of impaired glucose tolerance, and type 2 diabetes mellitus $(4,8)$. The etiology of PCOS is not clear, but studies have suggested that PCOS appears to have a complex, multifactorial etiology in which a variety of predisposing genes interact with environmental factors to produce the disease $(9,10)$.

Serum paraoxonase 1 (PON1) is a calcium-dependent esterase/lactonase, which is and mainly synthesized by the liver and circulates within HDL particles $(11,12)$. PON1 has PON, arylesterase, and lactonase activities (11). The enzyme not only hydrolyzes several organophosphorus insecticides and nerve agents, which is involved in the protection against xenobiotic toxicity (12), but also inhibits LDL oxidation, increases macrophage-associated cholesterol efflux, and possesses antioxidant, anti-inflammatory, and anti-atherogenic properties $(11,13)$. Recent studies showed that the lactonase activity of PON1 could play important roles in hydrolyzing and detoxifying oxidative stress mediators. In addition, PON1 is able to hydrolyze homocysteine thiolactone and thus inhibit homocysteinylation of proteins, which could be involved 
in protecting against protein inactivation, cell damage, and atherosclerosis (12).

Several polymorphisms in the exons and promoter region of PON1 gene have been reported to influence its activity or concentration. There are two common polymorphisms in the coding region, which lead to a glutamine $\rightarrow$ arginine substitution at position 192 $(192 Q / R)$ and leucine $\rightarrow$ methionine substitution at position $55(55 \mathrm{~L} / \mathrm{M})$. The $\mathrm{T}$ to $\mathrm{C}$ exchange in position -108 is one of the several polymorphisms identified in the promoter region of PON1. The 192Q/R (rs662) polymorphism has been shown to affect PON1 activities in a substrate-dependent manner such that paraoxon $(14,15,16)$ is hydrolyzed in vitro more efficiently by the $\mathrm{R}$ isoform, whereas diazoxon, soman, sarin (15), and lipid peroxides $(11,12,17)$ are hydrolyzed more rapidly by the $\mathrm{Q}$ isoform, but there are contradictory data about the relationship between 192 isoforms and the rates of phenylacetate hydrolysis $(14,15,18)$. Both the PON1 $55 \mathrm{~L} / \mathrm{M}(\mathrm{rs} 854560)$ and the PON1 $-108 \mathrm{C} / \mathrm{T}$ (rs705379) variants are associated with variations in concentrations $(11,12,18)$. As genetic factors, including polymorphism, were found to explain more than $60 \%$ phenotypic variance in PON1 activity (14), PON1 genetic factors may have an important effect on the physiological function of PON1 and its association with diseases. Studies showed that some of the PON1 polymorphisms were associated with several disorders: the PON1 192Q/R polymorphism was associated with coronary heart disease $(19,20)$, ischemic stroke (21), Alzheimer's disease (11), and chronic kidney disease (22); the PON1 55L/M polymorphism was associated with Parkinson's disease (23); and the PON1 - 108C/T polymorphism was associated with increased serum glucose concentrations in nondiabetic patients (24).

Recent evidence has shown that extensive oxidative stress and the state of low-grade inflammation may play important roles in HA, insulin resistance, and metabolic and cardiovascular long-term complications of PCOS $(6,25)$. HDLs possess antioxidant, anti-inflammatory, and anti-atherogenic properties, while the enzymes associated with HDL including PON1 play a crucial role in antioxidant functions of HDL (13). However, up to now, only a few reports regarding the possible connection between the PON1 and PCOS are available. Dursun et al. (26) reported that serum PON activity was decreased in patients with PCOS compared with control women, and San Millan et al. (27) reported that homozygosity for $T$ alleles of the $-108 \mathrm{C} / \mathrm{T}$, but not $192 Q / R$ and $55 \mathrm{M} / \mathrm{L}$, polymorphism in PON1 was more frequent in women with PCOS $(n=72)$ compared with nonhyperandrogenic control women $(n=42)$ in Spain. In contrast with the previous reports, our recent study showed that the $-108 \mathrm{C} / \mathrm{T}$ polymorphism in the PON1 gene was not associated with the risk of PCOS in Chinese women (28). Chen et al. (29) studied a relationship between 23 single nucleotide polymorphisms in the PON1 gene and PCOS in north Chinese women in a genome-wide association study, but the study did not include rs662 and rs854560 sites. As genotype and allele frequencies for PON1 gene polymorphisms differ greatly among ethnic groups $(12,30)$, it is important to address whether there are any relationships between the $192 \mathrm{Q} / \mathrm{R}$ and the $55 \mathrm{~L} / \mathrm{M}$ polymorphisms and PCOS in Chinese women. Therefore, in this study, we investigated the genotype distribution of PON1 192Q/R and 55L/M polymorphisms in women from healthy and PCOS populations in a well-characterized Chinese population using relatively large sample sizes (610 cases and 503 controls).

\section{Materials and methods}

\section{Subjects}

Six hundred and ten patients with PCOS and 503 control women between 17 and 45 years of age during 2006 to 2011 were studied in south-west China. For genetic association study, we included all the patients $(n=610)$ and controls $(n=503)$. For association study between PON1 genotypes and hormonal, biochemical, and metabolic parameters, all recruited women were not taking any medication known to affect carbohydrate or lipid or hormone metabolism for at least 3 months before the study and were studied during the follicular phase of their menstrual cycle (progesterone level $<3 \mathrm{ng} / \mathrm{ml}$ ). In amenorrheic women, recent ovulation was excluded by progesterone measurement $(<3 \mathrm{ng} / \mathrm{ml})$. Therefore, the subgroups of patients and controls for the biochemical and metabolic measurements consisted of 406 and 341 subjects respectively. In addition, as 43 patients with PCOS and 112 control women did not do oral glucose tolerance test tests in the metabolic analysis groups, the subgroups of the patients and the controls for $2 \mathrm{~h}$ insulin and glucose measurements consisted of 363 and 229 subjects respectively. In general, the subgroups of the patients and the controls were comparable to the respective groups of total patients and controls in terms of clinical characteristics such as age, body mass index (BMI), Ferriman-Gallwey score (FG score), systolic and diastolic blood pressure (SBP and DBP), and the genotype frequencies of PON1 192Q/R and $55 \mathrm{~L} / \mathrm{M}$. All study participants gave their informed consent, and the study was approved by our institutional review board.

All patients with PCOS were recruited from the Outpatient Department of Reproductive Endocrinology of West China Second University Hospital at Sichuan University in Chengdu. Each patient with PCOS met the diagnostic criteria for PCOS based on the revised 2003 Rotterdam ESHRE/ASRM consensus criteria and exclusion of related disorders (3). Oligo- and/or anovulation was assessed as oligomenorrhea, i.e. less than eight cycles per year. Sonographic diagnosis of PCOS was confirmed if there were 12 or more follicles in each 
ovary measuring 2-9 $\mathrm{mm}$ in diameter and/or increased ovarian volume $(>10 \mathrm{ml})$. Hyperandrogenemia was assessed as total testosterone (TT) levels above the 95th percentile of the levels $(0.75 \mathrm{ng} / \mathrm{ml})$ detected in a group of normal menstruating women with normal cycles and/or clinically by the presence of obvious acne and/or hirsutism with the F-G score of more than $6(31,32)$. The diagnosis of PCOS was based on a patient having two of these three findings, with exclusion of congenital adrenal hyperplasias, androgen-secreting tumors, and Cushing's syndrome.

The control group consisted of infertile women due to salpingian obstruction or the husband's infertility and recruited from the above-mentioned Outpatient Department of the hospital during the same period. All women were clinically healthy who had regular menstrual cycles (shorter than 35 days), exhibited normal circulating androgen levels (TT $<0.75 \mathrm{ng} / \mathrm{ml}$ ), and the absence of obvious acne or hirsutism (F-G score <6) on physical examination.

None of the subjects had clinically evident chronic or acute diseases such as infection, tumors, thyroid dysfunction, cardiovascular disease, endometriosis, hyperprolactinemia, hypogonadotropic hypogonadism, or premature ovarian failure.

Clinical and anthropometrical variables including waist circumference, hip circumference, waist-to-hip ratio (WHR), BMI $\left(\mathrm{kg} / \mathrm{m}^{2}\right)$, blood pressure, and the degree of hirsutism and acne were measured or assessed in all subjects.

Blood samples were obtained in the morning after overnight fasting. Blood samples for genotype analysis were collected in tubes containing EDTA, centrifuged at $1500 \boldsymbol{g}$ for $15 \mathrm{~min}$, and blood cells were stored at $4{ }^{\circ} \mathrm{C}$.

\section{Genotype analysis}

Genomic DNA was isolated from the peripheral blood leukocytes of subjects according to the method of Erlich (33). The PON1 $192 Q / R$ and $55 L / M$ genotypes were determined by PCR amplification and restriction analysis. PCR (total volume $25 \mu \mathrm{l}$ ) contained genomic DNA template $(2.0 \mu \mathrm{l}$, about 30-80 ng), $200 \mu \mathrm{M}$ each of dNTP, $1.5 \mathrm{mM} \mathrm{MgCl}_{2}, 0.75 \mathrm{U}$ recombinant Taq polymerase (MBI Fermentas, Vilnius, Lithuania), and $0.30 \mu \mathrm{M}$ of each primer. For $192 \mathrm{Q} / \mathrm{R}$ genotype, a $99 \mathrm{bp}$ fragment was amplified using primers (34): forward, 5'-TAT TGT TGC TGT GGG ACC TGA G-3' and reverse 5'-CAC GCT AAA CCC AAA TAC ATC TC-3'; for 55L/M genotype, a $172 \mathrm{bp}$ fragment was amplified using primers: forward, 5'-CCT GCA ATA ATA TGA AAC AAC CTG-3' and reverse 5'-TGA AAG ACT TAA ACT GCC AGT C-3' (Genecor Biotech Co. Ltd., Shanghai, China). The PCR was performed in a MyCycler thermal cycler (Bio-Rad Laboratories, Inc.) as follows: predenaturation at $95^{\circ} \mathrm{C}$ for $3 \mathrm{~min}$, followed by 32 cycles of $45 \mathrm{~s}$ at $95^{\circ} \mathrm{C}, 45 \mathrm{~s}$ at $61{ }^{\circ} \mathrm{C}$, and $1 \mathrm{~min}$ at $72{ }^{\circ} \mathrm{C}$ for $192 \mathrm{Q} / \mathrm{R}$ genotyping; 30 cycles of $45 \mathrm{~s}$ at $95^{\circ} \mathrm{C}, 45 \mathrm{~s}$ at
$59{ }^{\circ} \mathrm{C}$, and $1 \mathrm{~min}$ at $72{ }^{\circ} \mathrm{C}$ for $55 \mathrm{~L} / \mathrm{M}$ genotyping; ending with a single 7 min extension step at $72{ }^{\circ} \mathrm{C}$. Four to five microliters of 99 or 172 bp PCR products were digested with 1U BspPI (AlwI) and Hin1II (NlaIII) (MBI Fermentas) for $4-16 \mathrm{~h}$ at $37^{\circ} \mathrm{C}\left(55^{\circ} \mathrm{C}\right.$ for BspPI) respectively, and digestion resulted in 64 and $35 \mathrm{bp}$ fragment for $192 \mathrm{R}$ allele and in a nondigested $99 \mathrm{bp}$ fragment for $192 \mathrm{Q}$ allele; 106 and $66 \mathrm{bp}$ fragment for $55 \mathrm{M}$ allele and in a nondigested $172 \mathrm{bp}$ fragment for $55 \mathrm{~L}$ allele. The products were analyzed by electrophoresis on a 10\% PAGE gel or $3.0 \%$ agarose gel and visualized by staining with ethidium bromide. For the purpose of quality control of the genotyping, 30\% of DNA samples were genotyped again by the different operator. Eleven DNA samples for $192 Q / R$ genotype and nine DNA samples for 55L/M genotype with low PCR yield were re-amplified.

\section{Analysis of hormonal and metabolic profiles}

The levels of serum FSH, LH, TT, estradiol $\left(\mathrm{E}_{2}\right)$, progesterone $(\mathrm{P})$, prolactin, cortisol, TSH, and the concentrations of fasting plasma insulin were measured by chemiluminescence assays (Immulite 2000; Diagnostic Products Corporation, Los Angeles, CA, USA). The concentrations of plasma total cholesterol, HDL-C, LDL-C, and triglyceride were measured by enzymatic assay (Boehringer) using a Hitachi 7600-010 automatic analyzer. Fasting glucose was measured by the glucose oxidase technique (Roche Diagnostics $\mathrm{GmbH}$ ). The intraand interassay coefficients of variation for all measurements were $<5$ and $10 \%$ respectively.

The estimate of insulin resistance was calculated by the homeostasis model assessment of insulin resistance index $(\mathrm{HOMA}-\mathrm{IR}=$ fasting glucose $(\mathrm{mmol} / \mathrm{l}) \times$ fasting insulin $(\mu \mathrm{U} / \mathrm{ml}) / 22.5)(35)$.

Atherogenic index (AI) was calculated using the following equation: $\mathrm{AI}=(\mathrm{TC}-(\mathrm{HDL}-\mathrm{C})) /(\mathrm{HDL}-\mathrm{C})(36)$.

\section{Statistical analysis}

Data were presented as mean \pm s.D. Differences in variables were evaluated by the independent sample $t$-test between PCOS and control subjects. Variables with asymmetric distribution were evaluated by nonparametric tests (Mann-Whitney $U$ test). $\chi^{2}$ analysis was used to test deviations of genotype distribution from Hardy-Weinberg equilibrium and to determine allele or genotype frequencies between patients and controls. Odds ratio (OR) and 95\% confidence intervals (CI) were calculated to test relative risk for PCOS associated with $R$ allele by $\chi^{2}$ analysis and logistic regression methods. ANOVA was used to estimate the effect of PON1 genotypes on clinical and metabolic parameters. A value of $P<0.05$ was considered to be statistically significant. All statistical analyses were performed using Statistical Program for Social Sciences (SPSS) 13.0 for Windows (Chicago, IL, USA). 


\section{Results}

\section{Clinical and biochemical characteristics of the study population}

In accordance with the revised 2003 Rotterdam ESHRE/ASRM consensus criteria, there were 251 cases $(41.15 \%)$ with oligo- and/or anovulation (OA) + HA + polycystic ovaries (PCO), 190 cases (31.15\%) with $\mathrm{OA}+\mathrm{PCO}, 134$ cases $(22 \%)$ with $\mathrm{OA}+\mathrm{HA}$, and 35 cases (5.7\%) with $\mathrm{HA}+\mathrm{PCO}$ in the PCOS group.

As shown in Table 1, BMI, waist circumference, WHR, F-G score, SBP, DBP, average ovarian volume, and the day of menstrual cycle at sampling were significantly higher and age was significantly lower in the PCOS group compared with the control group.

P, TT, and LH levels; the ratio of LH to FSH; fasting and $2 \mathrm{~h}$ insulin and glucose concentration; HOMA index; TC, TG, and LDL-C levels; AI; and the ratio of TG to HDL-C were significantly higher, and FSH and HDL-C levels were significantly lower in patients with PCOS in comparison with the control group, although there was no significant difference with respect to $\mathrm{E}_{2}$ levels between the two groups (Table 2).

\section{Distribution of PON1 192Q/R and 55L/M genotypes and alleles}

Genotypic and allelic frequencies of PON1 192Q/R and $55 \mathrm{~L} / \mathrm{M}$ gene sites are summarized in Table 3. Genotypic distributions were in Hardy-Weinberg equilibrium in the PCOS and control groups. No significant differences were found in the frequencies of PON1 $55 \mathrm{~L} / \mathrm{M}$ genotypes and alleles between PCOS and control groups $(P>0.05)$. However, the prevalence of the PON1 $192 R R$ genotype was significantly more frequent in patients with PCOS compared with those in the control women ( 44.6 vs $36.4 \%, P=0.016$ ). There was also a significant difference in PON1 192Q/R allelic frequencies between PCOS and control subjects $(0.667$ vs 0.610 for $R$ allele, $P=0.005)$. Logistic regression

Table 1 Clinical characteristics in patients with PCOS and control women. Values are presented as mean \pm s.D.

\begin{tabular}{lccc}
\hline & $\begin{array}{c}\text { Controls } \\
(n=503)\end{array}$ & $\begin{array}{c}\text { PCOS } \\
(n=610)\end{array}$ & $\boldsymbol{P}$ \\
\hline Age (years) & $28.25 \pm 4.12$ & $24.72 \pm 4.02$ & 0.000 \\
BMI (kg/m $\left.{ }^{2}\right)$ & $20.92 \pm 2.67$ & $22.63 \pm 4.01$ & 0.000 \\
WC (cm) & $73.61 \pm 7.71$ & $78.21 \pm 10.95$ & 0.000 \\
WHR & $0.82 \pm 0.06$ & $0.85 \pm 0.07$ & 0.000 \\
F-G score & $0.20 \pm 0.65$ & $1.68 \pm 2.03$ & 0.000 \\
SBP (mmHg) & $113.12 \pm 10.69$ & $114.51 \pm 10.42$ & 0.032 \\
DBP (mmHg) & $74.25 \pm 8.05$ & $75.51 \pm 7.90$ & 0.009 \\
Ovarian volume (ml) & $7.32 \pm 2.54$ & $9.81 \pm 4.34$ & 0.000 \\
Menstrual cycle at & $12.51 \pm 14.09$ & $52.18 \pm 59.54$ & 0.000 \\
$\quad$ sampling (days) & & & \\
\hline
\end{tabular}

WC, waist circumference; WHR, waist-to-hip ratio. analysis adjusted for age, BMI, LDL, HDL, TG, and HOMA-IR also showed that the relative risk of subjects with $R R$ genotypes for PCOS was higher compared with those with $R R+Q R$ genotype $(\mathrm{OR}=1.656,95 \% \mathrm{CI}$ : $1.156-2.371, P=0.006)$.

We also analyzed the frequencies of haplotype combination genotypes of PON1 $55 \mathrm{M} / \mathrm{L}$ and $192 \mathrm{Q} / \mathrm{R}$ in patients with PCOS and the control women. The results show that the frequencies of haplotype combination $L-R / L-R$ genotype is $44.8 \%$ in patients with PCOS and significantly higher than $36.4 \%$ in the control women, and the haplotype containing both variations $M-R$ is not observed (Table 4). The multinomial logistic regression analysis shows that the haplotype combination $L-R / L-R$ genotype is a risk factor for $\mathrm{PCOS} \quad(\mathrm{OR}=1.646,95 \%$ CI: $1.102-2.460$, $P=0.015$, Table 4) when the $L-Q / L-Q$ wild-type i the reference category.

\section{Effects of PON1 192Q/R and 55L/M genetic variants on clinical, hormonal, and metabolic parameters}

Table 5 shows the influences of PON1 192Q/R genetic variant on clinical, hormonal, and metabolic parameters. Compared with patients with $Q Q$ genotype, patients with $R R$ or $Q R$ genotype had significantly higher waist circumference, fasting insulin, and TG levels $(P<0.05)$ and tended to have higher BMI, AI, and the ratio of TG to HDL-C $(P<0.10)$; patients with $R R$ genotype had significantly higher WHR $(P<0.05)$; and patients with $Q R$ genotype had significantly higher HOMA-IR $(P<0.05)$. However, there were no significant differences in clinical, biochemical, and metabolic parameters according to PON1 $192 Q / R$ genotypes in the control women $(P>0.05)$. In addition, in subjects with normal body weight $(\mathrm{BMI}<25)$, compared with the patients with $Q Q$ genotype $(n=37), R R$ genotype $(n=134)$, or $Q R$ genotype $(n=124)$ have significantly higher TT levels $(0.72 \pm 0.23$ or $0.70 \pm 0.20$ vs $0.61 \pm$ $0.22 \mathrm{ng} / \mathrm{ml}$, all $P<0.05$ ), and the patients with $R R$ genotype have higher WC $(75.45 \pm 7.22$ vs $72.70 \pm$ $6.27 \mathrm{~cm}, P<0.05)$.

Patients with $55 \mathrm{LM}$ heterozygotes had lower F-G score $(P=0.011)$ and tended to have lower BMI and $2 \mathrm{~h}$ insulin levels when compared with patients with 55LL homozygotes $(P<0.07)$. No significant differences in clinical, biochemical, and metabolic parameters according to PON1 55M/L genotypes were detected in the control women $(P>0.05)$ (Supplementary Table 1, see section on supplementary data given at the end of this article).

We further analyzed the relationships between the haplotype combination genotypes of PON1 $55 \mathrm{M} / \mathrm{L}$ and $192 Q / R$ and clinical and biochemical parameters in patients with PCOS. The results show that the patients with $L-R / L-R$ genotype $(n=186)$ have significantly higher WC and WHR when compared with the $L-Q / L-Q$ 
Table 2 Hormonal levels and metabolic profile in patients with PCOS and control women. Values are presented as mean \pm S.D.

\begin{tabular}{|c|c|c|c|}
\hline & $\begin{array}{l}\text { Controls } \\
(n=341)\end{array}$ & $\begin{array}{l}\text { PCOS } \\
(n=406)\end{array}$ & $P$ \\
\hline Age (years) & $27.92 \pm 4.06$ & $24.71 \pm 4.03$ & 0.000 \\
\hline BMl $\left(\mathrm{kg} / \mathrm{m}^{2}\right)$ & $20.79 \pm 2.60$ & $22.88 \pm 4.22$ & 0.000 \\
\hline $\begin{array}{l}\text { Menstrual cycle at } \\
\text { sampling (days) }\end{array}$ & $6.94 \pm 4.24$ & $62.75 \pm 66.24$ & 0.000 \\
\hline \multicolumn{4}{|l|}{ Hormonal levels } \\
\hline $\mathrm{E}_{2}(\mathrm{pg} / \mathrm{ml})$ & $95.42 \pm 104.78$ & $85.41 \pm 84.40$ & 0.964 \\
\hline $\mathrm{P}(\mathrm{ng} / \mathrm{ml})$ & $0.77 \pm 0.39$ & $0.91 \pm 0.63$ & 0.003 \\
\hline TT $(\mathrm{ng} / \mathrm{ml})$ & $0.43 \pm 0.15$ & $0.70 \pm 0.22$ & 0.000 \\
\hline LH (mlU/ml) & $7.72 \pm 9.30$ & $14.02 \pm 11.89$ & 0.000 \\
\hline $\mathrm{FSH}(\mathrm{mlU} / \mathrm{ml})$ & $6.27 \pm 2.66$ & $5.76 \pm 2.42$ & 0.011 \\
\hline LH/FSH & $1.27 \pm 1.25$ & $2.48 \pm 1.33$ & 0.000 \\
\hline \multicolumn{4}{|l|}{ Metabolic profile } \\
\hline Fasting Ins $(\mu \mathrm{U} / \mathrm{ml})$ & $9.27 \pm 5.26$ & $14.65 \pm 10.10$ & 0.000 \\
\hline Fasting Glu (mmol/l) & $5.31 \pm 0.49$ & $5.41 \pm 0.61$ & 0.015 \\
\hline $2 \mathrm{~h}$ Ins $(\mu \mathrm{U} / \mathrm{ml})^{\mathrm{a}}$ & $51.27 \pm 42.00$ & $102.44 \pm 81.93$ & 0.000 \\
\hline $2 \mathrm{~h}$ Glu $(\mathrm{mmol} / \mathrm{l})^{\mathrm{a}}$ & $6.04 \pm 1.32$ & $7.12 \pm 2.31$ & 0.000 \\
\hline HOMA-IR & $2.23 \pm 1.42$ & $3.65 \pm 3.08$ & 0.000 \\
\hline TG (mmol/l) & $1.14 \pm 1.01$ & $1.36 \pm 1.09$ & 0.000 \\
\hline $\mathrm{TC}(\mathrm{mmol} / \mathrm{l})$ & $4.23 \pm 0.72$ & $4.40 \pm 0.84$ & 0.002 \\
\hline HDL-C (mmol/l) & $1.51 \pm 0.32$ & $1.39 \pm 0.36$ & 0.000 \\
\hline LDL-C (mmol/l) & $2.25 \pm 0.63$ & $2.55 \pm 0.77$ & 0.000 \\
\hline $\mathrm{Al}$ & $1.89 \pm 0.70$ & $2.34 \pm 0.99$ & 0.000 \\
\hline TG/HDL-C & $0.75 \pm 0.54$ & $1.15 \pm 1.40$ & 0.001 \\
\hline
\end{tabular}

$\mathrm{Al}$, atherogenic index. Ins, insulin; Glu, glucose.

${ }^{\mathrm{a}}$ Control $(n=229)$, PCOS $(n=363)$.

wild types $(n=38)$ or the $M-Q / L-Q$ genotypes $(n=4)$ (WC: $80.26 \pm 11.14$ vs $75.11 \pm 8.54$ or 68.75 $\pm 5.56 \mathrm{~cm}$; WHR: $0.86 \pm 0.07$ vs $0.83 \pm 0.06$ or $0.77 \pm 0.04$; all $P<0.05)$. The patients with $L-R / L-R$ genotype or $M-Q / L-R$ genotype $(n=19)$ have higher TT levels when compared with the $M-Q / L-Q$ genotypes $(0.71 \pm 0.22$ or $0.72 \pm 0.23$ vs $0.48 \pm 0.26 \mathrm{ng} / \mathrm{ml}$, all $P<0.05)$ but not significant differences in glucose and lipid metabolic parameters $(P>0.05)$.

\section{Discussion}

In this study, we show that an association exists between the PON1 $192 Q / R$, but not $55 \mathrm{~L} / \mathrm{M}$, genetic polymorphism and the risk of PCOS in Chinese women, suggesting that this polymorphism may predispose to the disease susceptibility and potentially link to related complications responsible for oxidative stress and inflammation such as an increased risk for type 2 diabetes mellitus and/or future cardiovascular diseases in the patients.

Although the potential contributions of the genetic components to PCOS remain to be characterized, the increased systemic low-grade inflammation, one of the important pathological conditions of the disease, is thought to be multifactorial, involving the interaction of genetic and environmental influences. Human and animal studies strongly support the hypothesis that oxidative modification of lipoproteins, especially LDL, plays an important role in the onset of chronic inflammation and the pathogenesis of atherosclerosis (13). Therefore, mechanisms preventing oxidation of lipoproteins appear to be anti-inflammatory and antiatherogenic. HDLs were believed to be one of the most important defenses against lipid peroxides in the circulatory system because the enzymes associated with HDL, including PON1 and platelet-activating factor acetylhydrolase (PAF-AH), play a crucial role in antioxidant functions of HDL (13). Our previous studies showed that HDL-associated PAF-AH activity was decreased in women with PCOS and the PAF-AH G994 $\rightarrow$ T gene mutation, which leads to completely abolish PAF-AH activity, and is a risk factor for PCOS $(32,37,38)$. In this study, we found that the $192 Q / R$ polymorphism in PON1 gene was associated with the risk of PCOS in Chinese women, suggesting that the dysfunction of PON1 may also be involved in the pathophysiological process of the disease.

There is sufficient evidence that PON1 status on HDL in circulation is regulated by PON1 genetic polymorphisms (12). Studies have found that the PON1 192Q/R polymorphism itself does not affect PON1 protein concentrations but greatly influences PON1 activities, especially PON and lactonase activities (12, 39). HDL containing R192 PON1 isoform presents the highest PON activity, which is able to hydrolyze organophosphorus insecticide paraoxon, but the lowest lactonase activity, which is associated with hydrolysis of lipid peroxides (14). This suggests that the effects of $Q 192 R$ polymorphism on PON and lactonase activities of PON1 are opposite. In addition, there are contradictory data about the rates of PON1 phenylacetate hydrolysis (arylesterase activity), which is in a linear relationship with PON1 expression level $(18,40)$. Phenylacetate is hydrolyzed at

Table 3 Frequencies of PON1 genotype and allele in patients with PCOS compared with control women. Data of genotype are presented as number (\%) of patients or controls.

\begin{tabular}{|c|c|c|c|c|}
\hline & $\begin{array}{l}\text { Controls } \\
(n=503)\end{array}$ & $\begin{array}{c}\text { PCOS } \\
(n=610)\end{array}$ & $\chi^{2}$ & $P$ \\
\hline \multicolumn{5}{|c|}{ Genotype } \\
\hline \multicolumn{5}{|c|}{192} \\
\hline$Q Q$ & 72 (14.3\%) & $68(11.1 \%)$ & & \\
\hline$Q R$ & 248 (49.3\%) & 270 (44.3\%) & & \\
\hline$R R^{a}$ & $183(36.4 \%)$ & $272(44.6 \%)$ & 8.247 & 0.016 \\
\hline \multicolumn{5}{|l|}{55} \\
\hline$L L$ & $472(93.8 \%)$ & 569 (93.3\%) & & \\
\hline$L M$ & $31(6.2 \%)$ & $41(6.7 \%)$ & & \\
\hline$M M$ & $0(0.0 \%)$ & $0(0.0 \%)$ & 0.142 & 0.706 \\
\hline \multicolumn{5}{|c|}{ Allele frequency } \\
\hline \multicolumn{5}{|c|}{192} \\
\hline$Q$ & 0.390 & 0.333 & & \\
\hline$R$ & 0.610 & 0.667 & 7.755 & 0.005 \\
\hline \multicolumn{5}{|l|}{55} \\
\hline$L$ & 0.969 & 0.966 & & \\
\hline$M$ & 0.031 & 0.034 & 0.137 & 0.711 \\
\hline
\end{tabular}

${ }^{a}$ Odds ratio $(\mathrm{OR})_{\mathrm{RR} / \mathrm{QR}+\mathrm{QQ}} 1.226,95 \%$ confidence interval 1.060-1.418, $\chi^{2}=7.686, P=0.006$. 
Table 4 Frequencies of haplotype combination genotypes of $P O N 155 \mathrm{M} / \mathrm{L}$ and $192 Q / R$ in patients with PCOS and the control women. Odds ratio (OR) and $95 \%$ confidence interval $(\mathrm{Cl})$ were calculated in a multinomial logistic regression model wild-type $L-Q / L-Q$ as the reference category. A haplotype containing both variations $55 M-192 R$ was not observed.

\begin{tabular}{lccccc}
\hline $\begin{array}{l}\text { Haplotype } \\
\text { combination }\end{array}$ & Controls $(n=503)$ & PCOS $(n=610)$ & OR & 95\% Cl & $\boldsymbol{P}$ \\
\hline L-Q/L-Q & $64(12.7 \%)$ & $58(9.5 \%)$ & 1.00 & - & - \\
L-R/L-R & $183(36.4 \%)$ & $273(44.8 \%)$ & 1.646 & $1.102-2.460$ & 0.015 \\
L-R/L-Q & $225(44.7 \%)$ & $239(39.2 \%)$ & 1.172 & $0.786-1.747$ & 0.436 \\
M-Q/L-R & $23(4.6 \%)$ & $31(5.1 \%)$ & 1.487 & $0.780-2.837$ & 0.228 \\
M-Q/L-Q & $8(1.6 \%)$ & $9(1.5 \%)$ & 1.241 & $0.449-3.431$ & 0.667 \\
\hline
\end{tabular}

$L-Q$, the haplotype containing both variations $55 L-192 Q ; L-R$, the haplotype containing both variations $55 L-192 R ; M-Q$, the haplotype containing both variations $55 M-192 Q$. Data of haplotype combinations are presented as number (\%) of patients or controls, $\chi^{2}$ test: $\chi^{2}=9.526, P=0.049$.

approximately the same rate by both $\mathrm{Q}$ and $\mathrm{R}$ isoforms (15), more rapidly by the $\mathrm{Q}$ isoform (18), or more rapidly by the R isoform (14). As PON1 R192 allele has been reported to be in linkage disequilibrium with the PON1 $108 \mathrm{C}$ allele $(14,18)$, it is possible that the PON1 $-108 \mathrm{C}$ allele that increases PON1 expression may partly compensate for the PON1 arylesterase activities afforded by the $\mathrm{R}$ isoform in some cases.

Recent studies have shown that the native activity of PON1 is lactonase activity and the physiological function of PON1 in vivo is the degradation of oxidized lipids (11). HDL with PON1 R192 isoform has lower lactonase activity and is less efficient at retarding the oxidation of LDL when compared with HDL with Q192 PON1 isoform $(12,41)$. These results indicate that 192RR homozygosity has the lowest activity for hydrolyzing lipid peroxides, thus lowest anti-inflammatory and anti-atherogenic property. It has been reported that increased oxidative stress is able to induce insulin resistance by mediating serine phosphorylation of the insulin receptor substrates (IRS)-1 and -2, which leads to an abrogation of insulin signaling via its receptor (25). Our results that patients with $192 \mathrm{R}$ alleles had higher (or tended to increase) fasting insulin levels, HOMR-IR, and the ratio of TG to HDL-C, a marker of the small dense LDL particles that predispose to

Table 5 Clinical characteristics, hormonal levels, and metabolic profile according to PON1 Q192R genotype in patients with PCOS and control women. Values are presented as mean \pm S.D.

\begin{tabular}{|c|c|c|c|c|c|c|}
\hline & \multicolumn{3}{|c|}{ Control group } & \multicolumn{3}{|c|}{ PCOS group } \\
\hline & $Q Q(n=54)$ & $Q R(n=173)$ & $R R(n=114)$ & $Q Q(n=43)$ & $Q R(n=178)$ & $R R(n=185)$ \\
\hline \multicolumn{7}{|l|}{ Clinical characteristics } \\
\hline Age (years) & $27.26 \pm 4.42$ & $27.95 \pm 4.13$ & $28.19 \pm 3.77$ & $24.02 \pm 4.14$ & $25.07 \pm 4.02$ & $24.51 \pm 4.00$ \\
\hline $\mathrm{BMl}\left(\mathrm{kg} / \mathrm{m}^{2}\right)$ & $21.06 \pm 2.81$ & $20.62 \pm 2.45$ & $20.92 \pm 2.72$ & $21.68 \pm 3.75$ & $22.99 \pm 4.20$ & $23.05 \pm 4.32$ \\
\hline WC $(\mathrm{cm})$ & $74.43 \pm 8.20$ & $73.27 \pm 7.48$ & $72.77 \pm 7.48$ & $74.58 \pm 8.38$ & $78.68 \pm 11.92^{\mathrm{a}}$ & $80.36 \pm 11.12^{\mathrm{a}}$ \\
\hline WHR & $0.82 \pm 0.06$ & $0.82 \pm 0.06$ & $0.82 \pm 0.07$ & $0.83 \pm 0.06$ & $0.85 \pm 0.08$ & $0.86 \pm 0.07^{\mathrm{a}}$ \\
\hline F-G score & $0.11 \pm 0.42$ & $0.26 \pm 0.71$ & $0.27 \pm 0.81$ & $1.31 \pm 1.60$ & $1.78 \pm 2.16$ & $1.63 \pm 1.97$ \\
\hline Ovarian volume $(\mathrm{ml})$ & $8.15 \pm 3.57$ & $7.27 \pm 2.29$ & $7.95 \pm 2.54$ & $9.47 \pm 4.30$ & $9.74 \pm 4.23$ & $10.46 \pm 4.83$ \\
\hline \multicolumn{7}{|l|}{ Hormonal levels } \\
\hline $\mathrm{TT}(\mathrm{ng} / \mathrm{ml})$ & $0.43 \pm 0.16$ & $0.42 \pm 0.14$ & $0.45 \pm 0.16$ & $0.66 \pm 0.27$ & $0.70 \pm 0.20$ & $0.71 \pm 0.22$ \\
\hline $\mathrm{FSH}(\mathrm{mlU} / \mathrm{ml})$ & $6.03 \pm 1.84$ & $6.43 \pm 3.10$ & $6.14 \pm 2.19$ & $6.08 \pm 1.72$ & $5.83 \pm 2.89$ & $5.61 \pm 2.03$ \\
\hline $\mathrm{LH}(\mathrm{mlU} / \mathrm{ml})$ & $6.32 \pm 3.19$ & $8.29 \pm 11.01$ & $7.48 \pm 8.12$ & $14.42 \pm 7.64$ & $13.88 \pm 10.05$ & $14.06 \pm 14.17$ \\
\hline $\mathrm{LH} / \mathrm{FSH}$ & $1.12 \pm 0.66$ & $1.28 \pm 1.15$ & $1.27 \pm 1.26$ & $2.44 \pm 1.36$ & $2.51 \pm 1.23$ & $2.47 \pm 1.43$ \\
\hline \multicolumn{7}{|l|}{ Metabolic profile } \\
\hline Ins0 $(\mu \mathrm{U} / \mathrm{ml})$ & $8.89 \pm 3.92$ & $9.23 \pm 5.40$ & $9.36 \pm 5.61$ & $11.24 \pm 6.69$ & $15.29 \pm 11.69^{a}$ & $14.79 \pm 9.80^{\mathrm{a}}$ \\
\hline Ins120 $(\mu \mathrm{U} / \mathrm{ml})^{\mathrm{b}}$ & $43.13 \pm 23.89$ & $51.47 \pm 36.39$ & $55.10 \pm 54.89$ & $94.52 \pm 72.71$ & $99.74 \pm 74.99$ & $106.88 \pm 90.06$ \\
\hline Glu0 (mmol/l) & $5.25 \pm 0.46$ & $5.35 \pm 0.44$ & $5.26 \pm 0.56$ & $5.40 \pm 0.97$ & $5.44 \pm 0.62$ & $5.37 \pm 0.47$ \\
\hline Glu120 (mmol/l/ $)^{b}$ & $5.79 \pm 1.34$ & $6.13 \pm 1.35$ & $6.03 \pm 1.26$ & $7.16 \pm 3.42$ & $7.03 \pm 2.02$ & $7.19 \pm 2.26$ \\
\hline HOMA-IR & $2.10 \pm 1.00$ & $2.26 \pm 1.45$ & $2.25 \pm 1.55$ & $2.85 \pm 2.53$ & $3.88 \pm 3.61^{\mathrm{a}}$ & $3.62 \pm 2.60$ \\
\hline $\mathrm{TG}(\mathrm{mmol} / \mathrm{l})$ & $0.93 \pm 0.39$ & $1.07 \pm 1.30$ & $1.04 \pm 0.66$ & $1.11 \pm 0.47$ & $1.41 \pm 1.24^{\mathrm{a}}$ & $1.36 \pm 1.02^{\mathrm{a}}$ \\
\hline $\mathrm{TC}(\mathrm{mmol} / \mathrm{l})$ & $4.10 \pm 0.70$ & $4.29 \pm 0.74$ & $4.21 \pm 0.68$ & $4.33 \pm 0.72$ & $4.47 \pm 0.90$ & $4.36 \pm 0.81$ \\
\hline HDL-C (mmol/l) & $1.50 \pm 0.31$ & $1.51 \pm 0.32$ & $1.53 \pm 0.32$ & $1.48 \pm 0.43$ & $1.38 \pm 0.32$ & $1.38 \pm 0.38$ \\
\hline LDL-C (mmol/l' & $2.25 \pm 0.55$ & $2.42 \pm 0.67$ & $2.30 \pm 0.59$ & $2.44 \pm 0.66$ & $2.60 \pm 0.82$ & $2.53 \pm 0.75$ \\
\hline & $1.79 \pm 0.48$ & $1.95 \pm 0.78$ & $1.85 \pm 0.65$ & $2.10 \pm 0.79$ & $2.39 \pm 0.97$ & $2.36 \pm 1.04$ \\
\hline TG/HDL-C & $0.66 \pm 0.38$ & $0.86 \pm 2.08$ & $0.75 \pm 0.67$ & $0.87 \pm 0.59$ & $1.18 \pm 1.44$ & $1.14 \pm 1.40$ \\
\hline
\end{tabular}

a $P<0.05$ compared with $Q Q$ genotype subgroup in patients with PCOS.

${ }^{\mathrm{b} C o n t r o l:} Q Q(n=38), Q R(n=115), R R(n=76)$; PCOS: $Q Q(n=40), Q R(n=154), R R(n=169)$. Ins, insulin; Glu, glucose. 
increase susceptibility to oxidative stress compared with patients with 192QQ genotype, suggest that the patients with $192 \mathrm{R}$ alleles may have relatively higher oxidative stress levels, which may induce insulin resistance. San Millan et al. (27) reported that homozygosity for $T$ alleles (decreased PON1 gene expression) of the PON1 $-108 \mathrm{C} / \mathrm{T}$ polymorphism presented with increased hirsutism scores and serum testosterone concentrations when compared with carriers of $-108 \mathrm{C}$ alleles. Our findings that in patients with normal body weight (BMI <25), the carriers with $192 R$ alleles have significantly higher TT levels when compared with the patients with $Q Q$ genotype, prompt that $192 R$ allele may also contribute to HA in these patients. In addition, studies have shown that $192 \mathrm{R}$ alleles were associated with increased risk of cardiovascular diseases (20). In this study, compared with patients with 192QQ genotype, the patients with $192 R$ alleles present with greater abdominal obesity and higher TG levels and tended to increased BMI and AI, suggesting that $192 R$ allele may also be associated with increased risks of metabolic and cardiovascular long-term complications of PCOS.

The PON1 55L/M influences both PON1 concentrations and activities. $L$ allele carriers have significantly higher PON1 mRNA and protein levels (12). Compared with 55MM genotype, 55LL homozygotes had higher PON and lactonase activities (14). However, there are evidences to show that the effects of PON1 55L/M polymorphism on PON1 concentrations and activities is not due to the amino acid change but is, rather, largely due to linkage disequilibrium with the $192 Q / R$ variants and the -108 regulatory region polymorphism $(14,18)$. In this study, the similar frequencies of PON1 $55 \mathrm{~L} / \mathrm{M}$ genotypes and alleles were shown between PCOS and control groups, suggesting that PON1 55L/M genetic polymorphism was not associated with the risk of PCOS. However, we found that F-G score was lower, and BMI and $2 \mathrm{~h}$ insulin levels tended to be decreased in patients with 55LM genotype when compared with patients with $55 L L$ genotype, implying that $M$ alleles seemed to have a beneficial effect on glucose metabolism and HA associated with phenotypes such as F-G score. Consistent with Cascorbi's findings (34), in this study, we found that a strong linkage disequilibrium exists between the $55 \mathrm{M}$ variant and the $192 \mathrm{Q}$ variant in PON1 gene because we did not observe the haplotype containing both variations 55M-192R. Moreover, we found that patients with haplotype combination $L-Q / L-Q$ or $M-Q / L-Q$ genotype had lower WC, WHR, and TT levels when compared with the $L-R / L-R$ genotypes, suggesting that the effects of $M$ alleles on F-G score and glucose metabolism might at least partly be due to a linkage disequilibrium between the $55 \mathrm{M}$ allele and the $192 Q$ allele in patients with PCOS. It is possible that the $192 Q$ allele that increases PON1 lactonase activity may partly compensate for the low protein expression levels of $55 \mathrm{M}$ alleles. It should be noted that there is a relatively low frequency of PON1 $55 \mathrm{M}$ variant in Chinese when compared with the frequency in people of European origin (34); further studies in other ethnic groups are needed to evaluate a possible effect of the PON1 55L/M polymorphism for patients with PCOS.

In addition, the allele frequencies for PON1 polymorphisms differ among ethnic groups (12, 18, 30). Environmental factors such as smoking, high-fat diet, and consumption of antioxidants may also affect PON1 status on HDL in circulation or PON1 expression (42). Therefore, it is possible that the relationships between PON1 polymorphism and PON1 activity or disease may be different among different populations.

Limitations of this study were that we could not determine PON1 status and the oxidative stress parameters. Further study to detect PON1 lactonase activity or/and protein levels, and the oxidative stress parameters, such as plasma levels of oxidized LDL, small dense LDL particles, malondialdehyde, and oxidative lipids, in patients with different genotypes may help to provide clues to the mechanisms responsible for the genetic association.

In summary, this study reports that the PON1 192Q/R, but not $55 \mathrm{~L} / \mathrm{M}$, genetic polymorphism is associated with PCOS among Chinese women. As this polymorphism has been shown to be associated with the increased susceptibility to oxidative stress and inflammation, which may contribute to both the pathogenesis of PCOS and the increased risks for type 2 diabetes mellitus and future cardiovascular diseases, antioxidant therapies and anti-inflammatory, as well as other measures as changes in diet and lifestyle, might be beneficial for women with PCOS and the effective preventive strategies against major complications in the patients.

\section{Supplementary data}

This is linked to the online version of the paper at http://dx.doi.org/10. 1530/EJE-11-0986.

\section{Declaration of interest}

The authors declare that there is no conflict of interest that could be perceived as prejudicing the impartiality of the research reported.

\section{Funding}

This work was supported by Chinese National Natural Science Foundation (81070463), Program for Changjiang Scholars and Innovative Research Team in University (IRT0935), and Research Seed Fund from West China Second Hospital of Sichuan University (to H Bai).

\section{Author contribution statement}

P Fan designed the experiments, analyzed the data, and wrote the paper. H Liu was responsible for patient screening. Y Wang, J Zhang, and $\mathrm{F}$ Zhang collected human samples and took part in the experiments. H Bai analyzed the results and revised the paper. All authors discussed the results and commented on the manuscript. 


\section{Acknowledgements}

We thank patients with PCOS and control women who donated blood samples for this study. We are thankful to You Li, De Hua Wan, Qi Song, and Qin Su for work performed to support this study.

\section{References}

1 Dokras A. Cardiovascular disease risk factors in polycystic ovary syndrome. Seminars in Reproductive Medicine 200826 39-44. (doi:10.1055/s-2007-992923)

2 Dhindsa G, Bhatia R, Dhindsa M \& Bhatia V. Insulin resistance, insulin sensitization and inflammation in polycystic ovarian syndrome. Journal of Postgraduate Medicine 200450 140-144.

3 The Rotterdam ESHRE/ASRM-sponsored PCOS consensus workshop group. Revised 2003 consensus on diagnostic criteria and long-term health risks related to polycystic ovary syndrome. Fertility and Sterility 200481 19-25. (doi:10.1016/fertnstert. 2003.10.004)

4 Moran L \& Teede H. Metabolic features of the reproductive phenotypes of polycystic ovary syndrome. Human Reproduction Update 200915 477-488. (doi:10.1093/humupd/dmp008)

5 Gonzalez F, Rote NS, Minium J \& Kirwan JP. Reactive oxygen species-induced oxidative stress in the development of insulin resistance and hyperandrogenism in polycystic ovary syndrome. Journal of Clinical Endocrinology and Metabolism 200691 336-340. (doi:10.1210/jc.2005-1696)

6 Repaci A, Gambineri A \& Pasquali R. The role of low-grade inflammation in the polycystic ovary syndrome. Molecular and Cellular Endocrinology 2011335 30-41. (doi:10.1016/j.mce. 2010.08.002)

7 Shaw LJ, Bairey Merz CN, Azziz R, Stanczyk FZ, Sopko G, Braunstein GD, Kelsey SF, Kip KE, Cooper-Dehoff RM, Johnson BD, Vaccarino V, Reis SE, Bittner V, Hodgson TK, Rogers W \& Pepine CJ. Postmenopausal women with a history of irregular menses and elevated androgen measurements at high risk for worsening cardiovascular event-free survival: results from the National Institutes of Health - National Heart, Lung, and Blood Institute sponsored Women's Ischemia Syndrome Evaluation. Journal of Clinical Endocrinology and Metabolism 200893 1276-1284. (doi:10.1210/jc.2007-0425)

8 Ovalle F \& Azziz R. Insulin resistance, polycystic ovary syndrome, and type 2 diabetes mellitus. Fertility and Sterility $2002 \mathbf{7 7}$ 1095-1105. (doi:10.1016/S0015-0282(02)03111-4)

9 Goodarzi MO. Looking for polycystic ovary syndrome genes: rational and best strategy. Seminars in Reproductive Medicine 200826 5-13. (doi:10.1055/s-2007-992919)

10 Escobar-Morreale HF, Luque-Ramirez M \& San Millan JL. The molecular-genetic basis of functional hyperandrogenism and the polycystic ovary syndrome. Endocrine Reviews 200526 251-282. (doi:10.1210/er.2004-0004)

11 Camps J, Marsillach J \& Joven J. The paraoxonases: role in human diseases and methodological difficulties in measurement. Critical Reviews in Clinical Laboratory Sciences 200946 83-106. (doi:10. 1080/10408360802610878)

12 Precourt LP, Amre D, Denis MC, Lavoie JC, Delvin E, Seidman E \& Levy E. The three-gene paraoxonase family: physiologic roles, actions and regulation. Atherosclerosis 2011214 20-36. (doi:10. 1016/j.atherosclerosis.2010.08.076)

13 Navab M, Ananthramaiah GM, Reddy ST, Van Lenten BJ, Ansell BJ, Fonarow GC, Vahabzadeh K, Hama S, Hough G, Kamranpour N, Berliner JA, Lusis AJ \& Fogelman AM. The oxidation hypothesis of atherogenesis: the role of oxidized phospholipids and HDL. Journal of Lipid Research 200445 993-1007. (doi:10.1194/jlr.R400001JLR200)

14 Rainwater DL, Rutherford S, Dyer TD, Rainwater ED, Cole SA, Vandeberg JL, Almasy L, Blangero J, Maccluer JW \& Mahaney MC. Determinants of variation in human serum paraoxonase activity. Heredity 2009102 147-154. (doi:10.1038/hdy.2008.110)
15 Davies HG, Richter RJ, Keifer M, Broomfield CA, Sowalla J \& Furlong $C E$. The effect of the human serum paraoxonase polymorphism is reversed with diazoxon, soman and sarin. Nature Genetics 199614 334-336. (doi:10.1038/ng1196-334)

16 Humbert R, Adler DA, Disteche CM, Hassett C, Omiecinski CJ \& Furlong CE. The molecular basis of the human serum paraoxonase activity polymorphism. Nature Genetics 19933 73-76. (doi:10. 1038/ng0193-73)

17 Mackness B, Durrington PN \& Mackness MI. Polymorphisms of paraoxonase genes and low-density lipoprotein lipid peroxidation. Lancet 1999353 468-469. (doi:10.1016/S0140-6736(98) 05105-8)

18 Brophy VH, Jampsa RL, Clendenning JB, McKinstry LA, Jarvik GP \& Furlong CE. Effects of $5^{\prime}$ regulatory-region polymorphisms on paraoxonase-gene (PON1) expression. American Journal of Human Genetics 200168 1428-1436. (doi:10. 1086/320600)

19 Bhattacharyya T, Nicholls SJ, Topol EJ, Zhang R, Yang X, Schmitt D, Fu X, Shao M, Brennan DM, Ellis SG, Brennan ML, Allayee H, Lusis AJ \& Hazen SL. Relationship of paraoxonase 1 (PON1) gene polymorphisms and functional activity with systemic oxidative stress and cardiovascular risk. Journal of the American Medical Association 2008299 1265-1276. (doi:10. 1001/jama.299.11.1265)

20 Wang M, Lang X, Zou L, Huang S \& Xu Z. Four genetic polymorphisms of paraoxonase gene and risk of coronary heart disease: a meta-analysis based on 88 case-control studies. Atherosclerosis 2011214 377-385. (doi:10.1016/j.atherosclerosis.2010.11.028)

21 Can Demirdogen B, Turkanoglu A, Bek S, Sanisoglu Y, Demirkaya S, Vural O, Arinc E \& Adali O. Paraoxonase/arylesterase ratio, PON1 192Q/R polymorphism and PON1 status are associated with increased risk of ischemic stroke. Clinical Biochemistry $2008 \mathbf{4 1}$ 1-9. (doi:10.1016/j.clinbiochem.2007.08.010)

22 Ichikawa K, Konta T, Emi M, Toriyama S, Takasaki S, Ikeda A, Shibata Y, Takabatake N, Takeishi Y, Kato T, Kawata S \& Kubota I. Genetic polymorphisms of paraoxonase-1 are associated with chronic kidney disease in Japanese women. Kidney International 200976 183-189. (doi:10.1038/ki.2009.97)

23 Zintzaras E \& Hadjigeorgiou GM. Association of paraoxonase 1 gene polymorphisms with risk of Parkinson's disease: a metaanalysis. Journal of Human Genetics $2004 \mathbf{4 9} 474-481$. (doi:10. 1007/s10038-004-0176-x)

24 Leviev I, Kalix B, Brulhart Meynet MC \& James RW. The paraoxonase PON1 promoter polymorphism $\mathrm{C}(-107) \mathrm{T}$ is associated with increased serum glucose concentrations in non-diabetic patients. Diabetologia $2001 \quad \mathbf{4}$ 1177-1183. (doi:10.1007/ s001250100610)

25 Evans JL, Maddux BA \& Goldfine ID. The molecular basis for oxidative stress-induced insulin resistance. Antioxidants $\mathcal{E}$ Redox Signaling 20057 1040-1052. (doi:10.1089/ars.2005.7.1040)

26 Dursun P, Demirtas E, Bayrak A \& Yarali H. Decreased serum paraoxonase 1 (PON1) activity: an additional risk factor for atherosclerotic heart disease in patients with PCOS? Human Reproduction 200621 104-108. (doi:10.1093/humrep/dei284)

27 San Millan JL, Corton M, Villuendas G, Sancho J, Peral B \& Escobar-Morreale HF. Association of the polycystic ovary syndrome with genomic variants related to insulin resistance, type 2 diabetes mellitus, and obesity. Journal of Clinical Endocrinology and Metabolism 2004 89 2640-2646. (doi:10.1210/jc.2003-031252)

28 Zhang F, Liu HW, Fan P, Bai H \& Song Q. The $-108 \mathrm{C} / \mathrm{T}$ polymorphism in paraoxonase 1 gene in Chinese patients with polycystic ovary syndrome. Sichuan Da Хие Хие Вао Yі Хие Ban 201142 24-28.

29 Chen ZJ, Zhao H, He L, Shi Y, Oin Y, Li Z, You L, Zhao J, Liu J, Liang X, Zhao X, Sun Y, Zhang B, Jiang H, Zhao D, Bian Y, Gao X, Geng L, Li Y, Zhu D, Sun X, Xu JE, Hao C, Ren CE, Zhang Y, Chen S, Zhang W, Yang A, Yan J, Ma J \& Zhao Y. Genome-wide association study identifies susceptibility loci for polycystic ovary syndrome on chromosome 2p16.3, 2p21 and 9q33.3. Nature Genetics 201143 55-59. (doi:10.1038/ng.732) 
30 Ginsberg G, Neafsey P, Hattis D, Guyton KZ, Johns DO \& Sonawane B. Genetic polymorphism in paraoxonase 1 (PON1): population distribution of PON1 activity. Journal of Toxicology and Environmental Health. Part B, Critical Reviews 200912 473-507. (doi:10.1080/10937400903158409)

31 Guo M, Chen ZJ, Macklon NS, Shi YH, Westerveld HE, Eijkemans MJ, Fauser BC \& Goverde AJ. Cardiovascular and metabolic characteristics of infertile Chinese women with PCOS diagnosed according to the Rotterdam consensus criteria. Reproductive Biomedicine Online 2010 21 572-580. (doi:10. 1016/j.rbmo.2010.04.032)

32 Fan P, Liu HW, Wang XS, Zhang F, Song Q, Li Q, Wu HM \& Bai H. Identification of the G994T polymorphism in exon 9 of plasma platelet-activating factor acetylhydrolase gene as a risk factor for polycystic ovary syndrome. Human Reproduction 201025 1288-1294. (doi:10.1093/humrep/deq047)

33 Erlich HA. PCR technology: principles and applications for DNA amplification, 1st edn. New York: Stockton Press, 1989.

34 Cascorbi I, Laule M, Mrozikiewicz PM, Mrozikiewicz A, Andel C, Baumann G, Roots I \& Stangl K. Mutations in the human paraoxonase 1 gene: frequencies, allelic linkages, and association with coronary artery disease. Pharmacogenetics 19999 755-761. (doi:10.1097/00008571-199912000-00010)

35 Matthews DR, Hosker JP, Rudenski AS, Naylor BA, Treacher DF \& Turner RC. Homeostasis model assessment: insulin resistance and beta-cell function from fasting plasma glucose and insulin concentrations in man. Diabetologia 198528 412-419. (doi:10. 1007/BF00280883)

36 Demirel F, Bideci A, Cinaz P, Camurdan MO, Biberoglu G, Yesilkaya E \& Hasanoglu A. Serum leptin, oxidized low density lipoprotein and plasma asymmetric dimethylarginine levels and their relationship with dyslipidaemia in adolescent girls with polycystic ovary syndrome. Clinical Endocrinology 200767 129-134. (doi:10.1111/j.1365-2265.2007.02849.x)
37 Fan P, Liu HW, Wan DH, Li Y, Song Q \& Bai H. Altered distribution of plasma platelet-activating factor acetylhydrolase between high-density lipoprotein and low-density lipoprotein in patients with polycystic ovary syndrome. Fertility and Sterility $2009 \mathbf{9 2}$ 2054-2057. (doi:10.1016/j.fertnstert.2009.06.022)

38 Fan P, Liu HW, Wang Y, Zhang F \& Bai H. Apolipoprotein E-containing high-density lipoprotein-associated platelet-activating factor-acetylhydrolase activities and malondialdehyde levels in patients with PCOS. Reproductive BioMedicine Online 201224 197-205. (doi:10.1016/j.rbmo.2011.10.010)

39 Leviev I \& James RW. Promoter polymorphisms of human paraoxonase PON1 gene and serum paraoxonase activities and concentrations. Arteriosclerosis, Thrombosis, and Vascular Biology 200020 516-521. (doi:10.1161/01.ATV.20.2.516)

40 Garin MC, James RW, Dussoix P, Blanche H, Passa P, Froguel P \& Ruiz J. Paraoxonase polymorphism Met-Leu 54 is associated with modified serum concentrations of the enzyme. A possible link between the paraoxonase gene and increased risk of cardiovascular disease in diabetes. Journal of Clinical Investigation 199799 62-66. (doi:10.1172/JCI119134)

41 Mackness B, Mackness MI, Arrol S, Turkie W \& Durrington PN. Effect of the human serum paraoxonase 55 and 192 genetic polymorphisms on the protection by high density lipoprotein against low density lipoprotein oxidative modification. FEBS Letters 1998423 57-60. (doi:10.1016/S0014-5793(98)00064-7)

42 Camps J, Marsillach J \& Joven J. Pharmacological and lifestyle factors modulating serum paraoxonase-1 activity. Mini Reviews in Medicinal Chemistry $20099911-920$.

Received 15 November 2011

Revised version received 15 January 2012

Accepted 2 February 2012 